\title{
Development of thymus autografts under the kidney capsule in the pig: A new "organ" for xenotransplantation
}

Lambrigts D, Franssen C, Martens H, Van Calster P, Meurisse M, Geenen V, Charlet-Renard C, Dewaele A, Coignoul F, Lamy M, Alexandre GPJ. Development of thymus autografts under the kidney capsule in the pig: A new "organ" for xenotransplantation. Xenotransplantation 1996; 3:296-303. (C) Munksgaard, Copenhagen

Abstract: Ten piglets, 7 to 16 weeks old, were partially thymectomised and 1 to $4 \mathrm{~cm}^{3}$ of minced thymic fragments autografted under the renal capsule. They were sacrificed, respectively, after 2, 4, 6, 8, 12, and 20 weeks. After 2 weeks, irregular whitish zones are present under the renal capsule. They were composed principally of two cell types: the first type was characterized by small round basophilic nuclei and little cytoplasm typical of lymphocytes; the second cell type had larger ovoid nuclei and a large vacuolised cytoplasm. Each cell type could be found in separate lobules or mixed in variable proportion in the same structure. The thymic autografts grew to form a layer up to $4 \mathrm{~mm}$ thick after 20 weeks. In the meantime, at the beginning of 4th week, the lobular structure became well organized with the cell type presenting large nuclei and cytoplasm being restricted to the center of the lobules while lymphocytes composed a peripheral layer. Hassal corpuscles (HC) appeared in the center of the lobules. Immunohistochemical labeling with anti-cytokeratin mono- and polyclonal $\mathrm{Ab}$ and with anti-neurophysin polyclonal $\mathrm{Ab}$ displayed all the characteristics of normal functional thymic microenvironment. It is proposed that this novel experimental preparation ending up as a neo-organ (thymo-kidney) be used for xenotransplantation in an attempt to produce specific xenotolerance.

\section{Lambrigts, C. Franssen, H. Martens, P. Van Calster, M. Meurisse, V. Geenen, C. Charlet-Renard, A. Dewaele, F. Coignoul, M. Lamy, and G.P.J. Alexandre}

"Centre Interdisciplinaire de Recherches en Xénotransplantation (CIREX)," University of Liège, Faculties of Medicine and Veterinarian Medicine, Boulevard de Colonster 20, 4000 Liège (Sart Tilman), Belgium

Key words: pig - baboon xenotransplantation - thymus - tolerance

Address reprint requests to $D r$. Lambrigts $D$, "Centre Interdisciplinaire de Recherches en Xénotransplantation (CIREX)," University of Liège, Faculty of Veterinarian Medicine, Boulevard de Colonster 20, Building 43, 4000 Liège (Sart Tilman), Belgium.

Accepted September 22, 1996.

\section{Introduction}

Organ transplantation has become the treatment of choice for a number of severe disorders but increasing organ shortage is depraving this modern therapeutic procedure from filling its goal. Xenotransplantation, if and when applicable, could solve most of the problems related to the present practice of organ transplantation. For several reasons, the pig represents the most valid candidate as a source of organs for human $[1,2]$. However, pig-to-man xenotransplantation being discordant [3], two immunological barriers need to be breached: hyperacute humoral rejection caused by natural xenoantibodies of man against antigens of the pig vascular endothelium and the more classical cellular rejection that is going to ensue. Contrarily to what was primarily thought, the latter will probably be stronger in xenografts than in allografts [4-7].

It has been shown that humoral rejection may be avoided by procedures aimed at eliminating natural antibodies responsible for hyperacute rejection of human ABO-incompatible allografts [8]. Hyperacute humoral rejection of discordant xenografts may be similarly avoided $[9,10]$. Moreover, the practice of ABO-incompatible allografts in man [11] taught us that a peculiar phenomenon is taking place in recipients receiving $\mathrm{ABO}$-incompatible allografts, while natural antibodies against the donor's vascular endothelium return after grafting but fail to initiate humoral rejection. The name of accommodation that was given by F.H. Bach [12] to this phenomenon fits well with what we believe is the underlying process, 


\section{New "organ" for xenotransplantation}

i.e., an adaptation of the endothelial cell protecting itself from the returning antibodies. There are reasons to believe that a similar accommodation could occur in discordant xenografts $[9,13]$.

Even if humoral rejection may be avoided, the control of cellular rejection of discordant xenografts treated with non-specific immunosuppression will place recipients at greater risk of infectious complications, limiting if not prohibiting the use of xenotransplants. Therefore, induction of specific immune tolerance to the xenogeneic organ donor may present itself as a prerequisite for clinical application of discordant xenotransplantation.

Xenotolerance through mixed chimerism has been obtained in concordant models $[14,15]$ with bone marrow transplantation but no long-term survival has been obtained so far by this method in discordant models. Sykes, Lee, Sachs, et al. [16,17] have induced xenotolerance to minipigs in immunocompetent thymectomized mice by implanting fetal thymus and liver fragments under the renal capsule. Although these results provide very favourable prospects for future clinical xenotransplantation, their feasibility remains to be confirmed in a model closer to man such as the preclinical model represented by pig-to-baboon xenografting.

Our working hypothesis is to xenograft simultaneously the thymus and kidney together as a single thymo-kidney organ that has been prepared in the original donor. This study is primarily designed as a first step to investigate the feasibility of obtaining well-functioning thymic autografts under the renal capsule in the pig donor.

\section{Material and methods}

\section{Animal characteristics and surgical procedures}

Belgian Landrace or crossbred Pietrain-Belgian Landrace 7- to 16 -week-old piglets $(8-31 \mathrm{~kg})$ were obtained from local piggeries. Prior to surgery, animals were tranquillized with Azaperone (Stresnil ${ }^{\mathrm{TM}}$ : Janssen-Cilag, Belgium) (2 mg/kg, i.m.). When adequate sedation was obtained, anesthesia was preinduced with ketamine, $4-5 \mathrm{mg} / \mathrm{kg}$, i.v. General anesthesia was then induced with a bolus of propofol (Diprivan ${ }^{\mathrm{TM}}$; Zeneca, Milan, Italy), 1-2 $\mathrm{mg} / \mathrm{kg}$ and maintained by continuous IV administration of propofol $(10 \mathrm{mg} / \mathrm{kg} / \mathrm{hr})$.

Eight animals underwent partial thymectomy performed through a midline cervicotomy: the major part of both cervical lobes were excised so as to obtain a quantity of thymic tissue sufficient for implantation under the renal capsule. In this group, unilateral engraftment was performed through a lumbar incision to expose both sides of the left kid- ney. Two additional animals underwent partial thymectomy and bilateral engraftment performed by midline laparotomy.

After excision, the thymic tissue was immersed in culture medium (RPMI 1640, Gibco BRL) until use. After exposure of the kidney, a $1 \mathrm{~cm}$ incision was done in the renal capsule opposite to the hilum. The renal capsule was detached from the cortex by blunt dissection with small smooth scissors on both sides of the kidney. Minced fragments of circa 1 $\mathrm{mm}^{3}$ were inserted under the capsule and gently pushed away from the incision by digital pressure allowing the fragments to glide to their final position. One to $4 \mathrm{~cm}^{3}$ of thymic tissue could be implanted under the renal capsule of each kidney, which was closed by a running 4-0 catgut suture and so was the peritoneum. The abdominal wall was closed in two layers.

Two animals were sacrificed respectively at 2, 4, 6 , and 8 weeks for renal examination. The two additional animals that were bilaterally engrafted were unilaterally nephrectomized at 12 weeks, the second kidney being removed at 20 weeks and the animal sacrificed.

\section{Pathology and immunofluorescence procedures}

Immediately after sacrifice or biopsy, tissue specimens were fixed in $10 \%$ buffered formalin, embedded in paraffin, and stained with haematoxylin and eosin (H\&E). Sections for immunochemistry were embedded with Tissue-Tek ${ }^{\mathrm{TM}}$ (Miles, Inc.) and directly frozen in liquid nitrogen.

Antibodies. Anti-human cytokeratin monoclonal $\mathrm{Ab}$ MNF 116 (lot 33) and rabbit polyclonal Abs anticytokeratin A575 (Lot 31 D) were obtained from Dako (Denmark). Rabbit polyclonal antiserum A5 IV (anti-neurophysine, NPs) was a kind gift of Professor JJ Legros (Neuroendocrinology Unit, Ulg-Liège, Belgium) and demonstrated to be specific of Exon-B encoded part of vasopressine- and oxytocineneurophysine [18]. O33 is a monoclonal antibody directed again the cyclic part of ocytocin (OT) [19]. Second antibodies were rhodamine (TRITC)-conjugated Affinipure goat anti-mouse IgG (lot 28970), hereafter referred to as second antibody $\mathrm{A}$, and fluorescein (FITC)-conjugated Affinipure $F\left(a b^{\prime}\right) 2$ fragment goat anti-rabbit IgG $(\mathrm{H}+\mathrm{L})$ (lot 27272), hereafter referred to as second antibody B. All conjugated Abs were obtained from Jackson ImmunoResearch Laboratories, Inc. (West Grove, Pennsylvania).

Biopsies for immunohistochemistry were cut in $8 \mu \mathrm{m}$ sections, which were treated according to the following procedures. Slices were stained for immunofluorescence after a $7 \mathrm{~min}$ in $20^{\circ} \mathrm{C}$ methanol fixation [20]. First incubation was $30 \mathrm{~min}$ at room 


\section{Lambrigts et al.}

temperature with $10 \%$ normal goat serum to prevent non-specific binding of goat second antibody to mouse or rabbit immunoglobulins. Single or double immunostaining was performed with the following reagent: anti-human cytokeratin $\mathrm{mAb}$ MNF 116 diluted at 1:50 followed by second antibody A; antineurophysin (A5 IV), diluted 1:100 followed by second antibody B. In some experiments MNF 116 was replaced by rabbit polyclonal anti-cytokeratin A575 diluted 1:200, followed by second antibody B diluted 1:100. Extinction controls were performed with second antibody alone, or after the first unrelated antibody. In the double immunostaining studies, the first step was always performed with first $\mathrm{mAb}$ followed by the appropriate second antibody prior to immunostaining with polyclonal antiserum. After the final wash, the plates were mounted with glycerol/gelatin medium. Immunostained cells were imaged using a Olympus fluorescence microscope.

All animals received humane care in compliance with the Belgian law relative to the welfare of experimental animals (Moniteur belge of 01/05/94, publication C-16190).

\section{Results}

Animals were divided into six groups depending on the moment at which tissue specimens were taken $(2,4,6,8,12$, and 20 weeks postop).

\section{Group 1}

Macroscopically, irregular whitish areas were observed under the renal capsule of animals sacrificed 2 weeks after transplantation. After incision, they appeared to be very thin (1-2 mm) with no evidence of renal tissue invasion. Light microscopic examination displayed hypercellular connective tissue and lobular basophilic structures. Connective tissue was composed of immature fibroblasts and neoformed blood vessels. Basophilic structures up to 30 cells thick were composed of two cell types, the first being characterized by small round basophilic nuclei and little cytoplasm, with the typical appearance of lymphocytes. The second cell type had basophilic, large ovoid nuclei and a prominent vacuolated cytoplasm. Each cell type could be found in separate lobules or mixed in variable proportion in the same structure. Slight infiltrates of lymphocytes, plasma cells, eosinophils, and adipocytes were also present in the connective tissue. Neither lymphoid infiltration nor other cell type infiltrate was observed in the renal cortex.

\section{Group 2}

Macroscopically, kidneys of animals sacrificed 4 weeks after transplantation showed similar areas to those described in group 1. After incision, they were thicker $(2-3 \mathrm{~mm})$ and firmer. Microscopically, the lobular lymphoid structures were larger, up to $1 \mathrm{~mm}$ and were composed of small lobular units separated with interstitial fibroblastic tissue. The two cell types previously described were present in each small lobular unit but with a particular pattern: only the cell type with large nuclei and cytoplasm was observed in the center of these units; lymphocytes composed a peripheral layer. Moreover, in the center of some lobular units, onion skin like structures composed of large, narrow cells with very small nuclei were seen, with the typical aspect of Hassal corpuscles (HC). Neoformed blood vessels were present in the interstitial tissue.

\section{Group 3}

Kidneys of animals sacrificed 6 weeks after transplantation showed the same macroscopic appearance as those after 4 weeks. Light microscopic examination displayed the same overall pattern with the same cell types and $\mathrm{HC}$ as described. The typical thymic structure with cortical, medullary areas, and $\mathrm{HC}$ was then obvious. The connective tissue was thinner, less cellular, and with more abundant collagen. The maximum outgrowth at this time was 2 mm thick.

\section{Group 4}

Kidneys of animals sacrificed 8 weeks after transplantation also showed the same macroscopic appearance (Fig. 1). Light microscopic examination displayed histologically normal thymus tissue up to $3 \mathrm{~mm}$ thick. In some areas, the connective tissue had almost disappeared, only a small layer of fibroblasts tissue being left around the engraftment (Fig. 2).

\section{Group 5}

Kidneys of animals biopsied 12 weeks after bilateral thymus autografting showed the same macroscopic appearance as previously described. Light microscopic finding was identical to group 4 but maximum thickness was only $2 \mathrm{~mm}$.

Fig. 1. Thymic autograft in a piglet, 8 weeks after implantation. The thymic tissue is well visible through the renal capsule and appears as a whitish, confluent, and irregular layer of tissue.

Fig. 2. Light microscopy of a thymic autograft, 8 weeks after implantation. The implant shows well organized thymic tissue with cortical and medullary areas and Hassal corpuscles. 


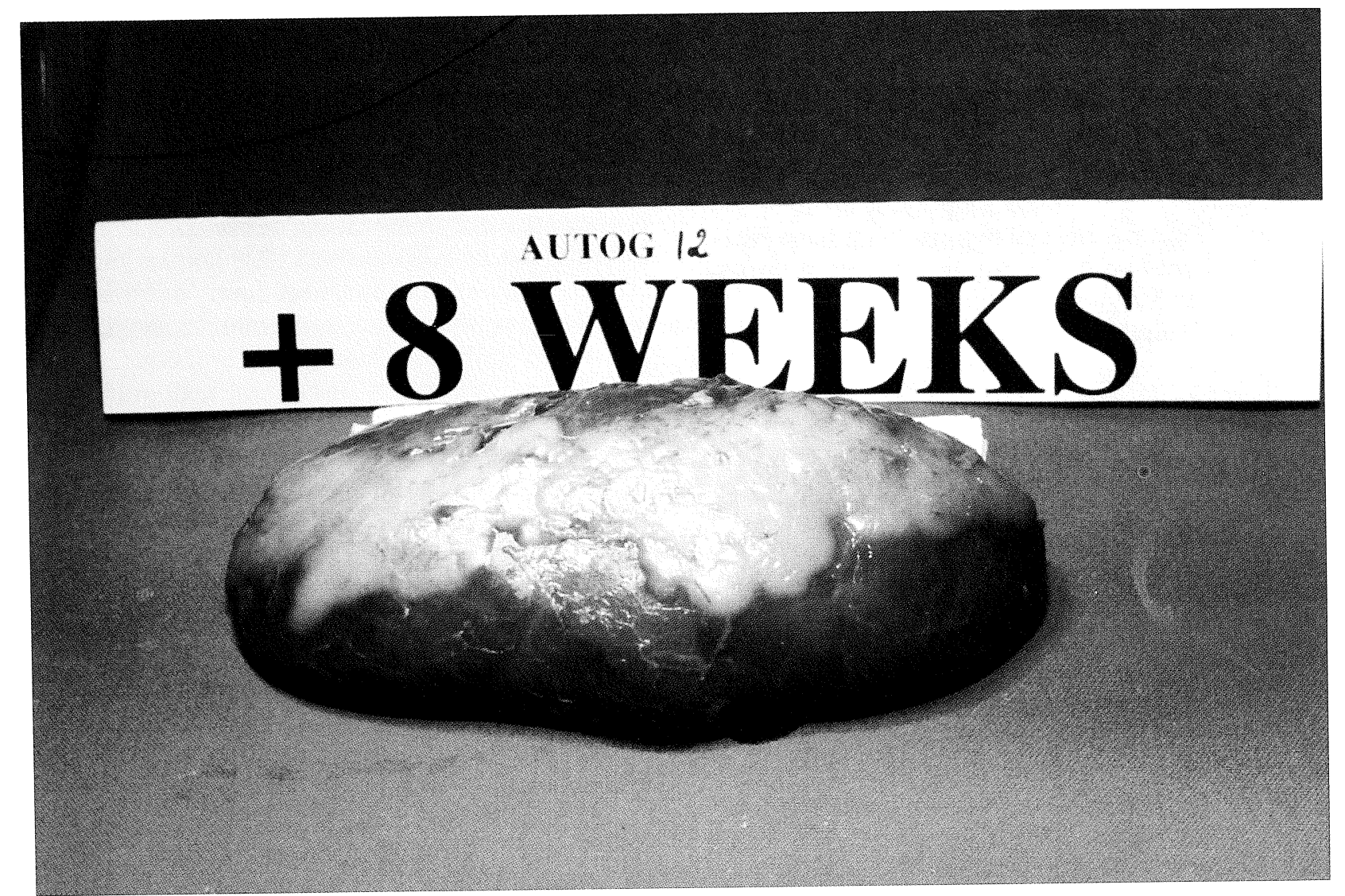

Figure 1.

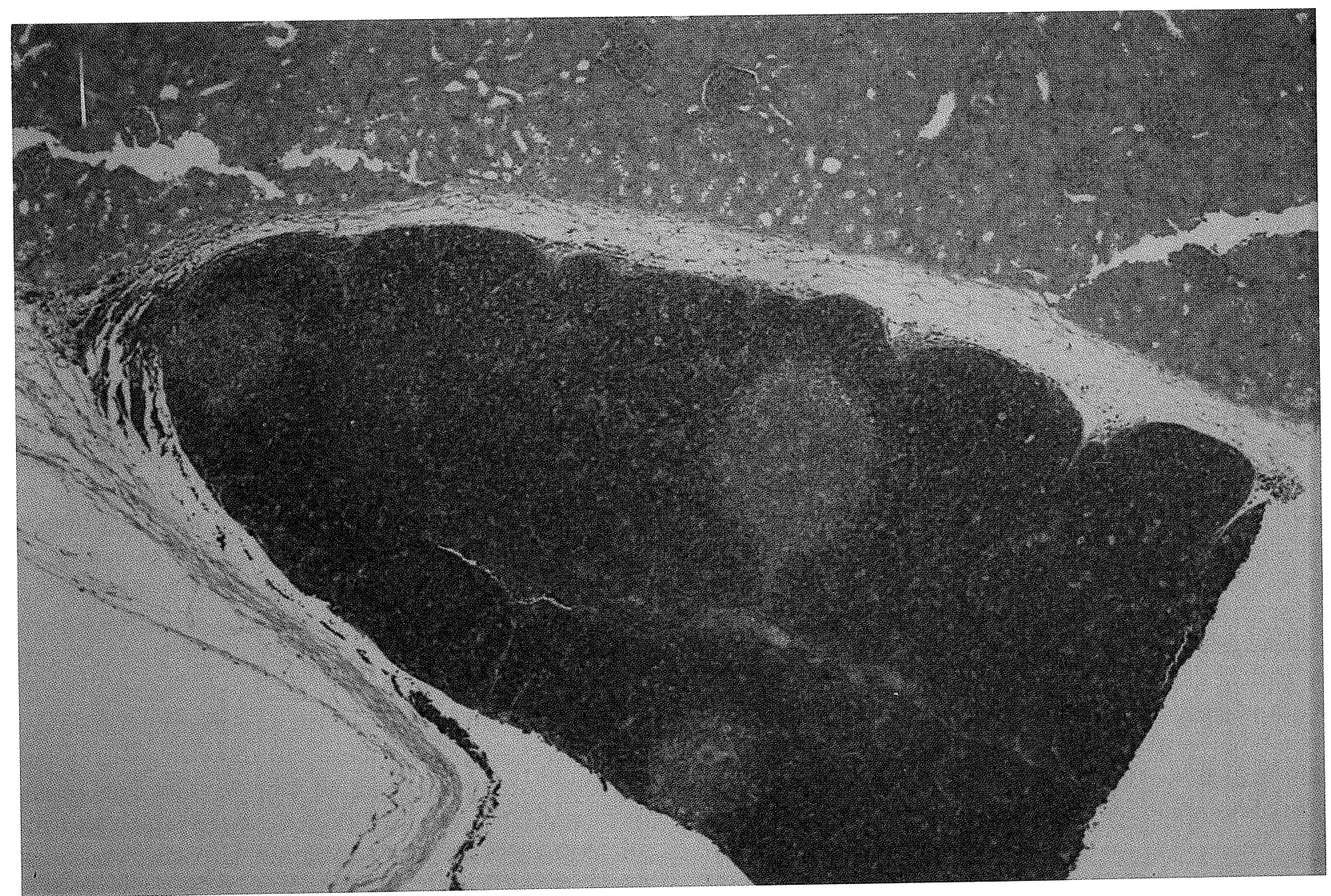

Figure 2. 


\section{Lambrigts et al.}

Group 6

Kidneys of animals biopsied 20 weeks after bilateral thymus autotransplantation showed the same macroscopic appearance as in groups 2 to 5 . Light microscopic examination displayed up to $4 \mathrm{~mm}$ thick histologically normal thymus, with large blood vessels. There was never any significant modification of the underlying renal cortex nor lymphoid infiltration of renal tissue.

\section{Cytokeratin (CK), ir-NPs, ir-OT immunofluorescence studies}

The immunohistochemical labeling with several antibodies described in materials and methods have been performed on the same tissues as for the $H \& E$ sections previously described. The staining obtained with anti-cytokeratin mAb MNF 116 shows the same pattern in all biopsies. We clearly observed a bright labeling on the engrafted tissues, while renal tissue is not stained except for some tubular structures. The epithelial CK-labelled tissues show the same lobular arrangement as described previously in the H\&E biopsies (Fig. 3A). In the immunoreactive areas, MNF 116 stained a monolayer of flattened cells lining the inner surface of the thymic capsule and lobular septae. In some areas, a dense reticular network of stellate cells with voluminous cytoplasm and short processes surrounded $\mathrm{HC}$; the centre of the $\mathrm{HC}$ is generally unreactive (Fig. 3C). Antiserum to neurophysin (A5IV) displayed a similar structure (Fig. 3B,D). Co-labeling with antiserum to CK A575 together with $\mathrm{mAb}$ to OT 033 shows essentially the same cellular organisation.

\section{Discussion}

Organ transplantation has become the treatment of choice for a number of severe disorders but due to ever increasing waiting lists, transplants are often performed in critically ill patients, too late to allow for satisfactory durable recovery. Those who benefit from a transplant still remain at risk of rejection or complication from non-specific immunosuppression.

Xenotransplantation represents the best solution of these problems. The pig is generally being considered as one of the most suitable organ donor species for man. However, clinical application of pig-to-man organ xenotransplantation, being of a discordant nature, will depend on the possibility to control both humoral and cellular aspects of rejection.

Hyperacute rejection of discordant xenografts has long been considered as an absolute barrier. Meanwhile, it has been demonstrated that hyperacute rejection may be avoided by eliminating recipient's xenoantibodies (XNA) prior to the transplant procedure by plasmapheresis [9], immunoadsorption [21,22], xenoperfusion [23], or by neutralizing XNA with oligosaccharides [24]. When recipient's XNA are allowed to return slowly after transplantation, it is hoped that accommodation, a concept that evolved from the use of $\mathrm{AB} 0$-incompatible human allografts [11], could also come into effect during the postoperative course of discordant xenotransplants [25] and protect the graft from humoral destruction.

Cellular rejection of discordant xenografts may be addressed by immunosuppression or better by induction of immunological tolerance. While in vitro experiments suggest that cell-mediated response in xenografts appears less aggressive than in allografts, data from in vivo experiments indicate the contrary to be true [7]. It is therefore doubtful that any scheme of immunosuppressive drug regimen will have sufficient clinical efficacy, while maintaining acceptable side effects for discordant xenotransplantation.

In our opinion, induction of specific immune xenotransplantation tolerance presents the only reasonable solution to resolve this matter; moreover, it could offer solutions to both B- and T-cell responses to xenografts. Xenotolerance, once induced, should maintain itself spontaneously, thereby avoiding the risks of long-term non-specific immunosuppression therapy. So far however, all the methods that have been used experimentally to induce tolerance in allotransplantation have been found either unreliable or too toxic for clinical application. The most limiting factors in developing such methods for clinical transplantation are either the need to avoid supplementary risks in the case of a living organ donor or the period of time between death of the donor and the transplant procedure that is too short to go into effect in the case of cadaveric organ transplantation.

On the contrary, one of the main advantages of xenotransplantation is the possibility of considering donor manipulations that would otherwise be prohibited in human allotransplantation. In this regard, it is well known that the thymus plays a central role in the development of tolerance to self. More recently, Sykes, Lee, Sachs, et al. [16,17] have shown that xenotolerance to pig antigens may be produced in immunocompetent thymectomized mice by implanting fetal thymus and liver under the renal capsule after whole body irradiation ( $3 \mathrm{~Gy}$ ) and immunosuppressive therapy with anti-T and anti-NK cell monoclonals. Similar growth of implanted thymic fragments under the renal capsule of thymectomized mice was obtained with thymus fragments retrieved from neonatal piglets. A suspension of fetal liver cells was administered simultaneously in these mice [26].

Thymectomy of mice before implantation of pig 

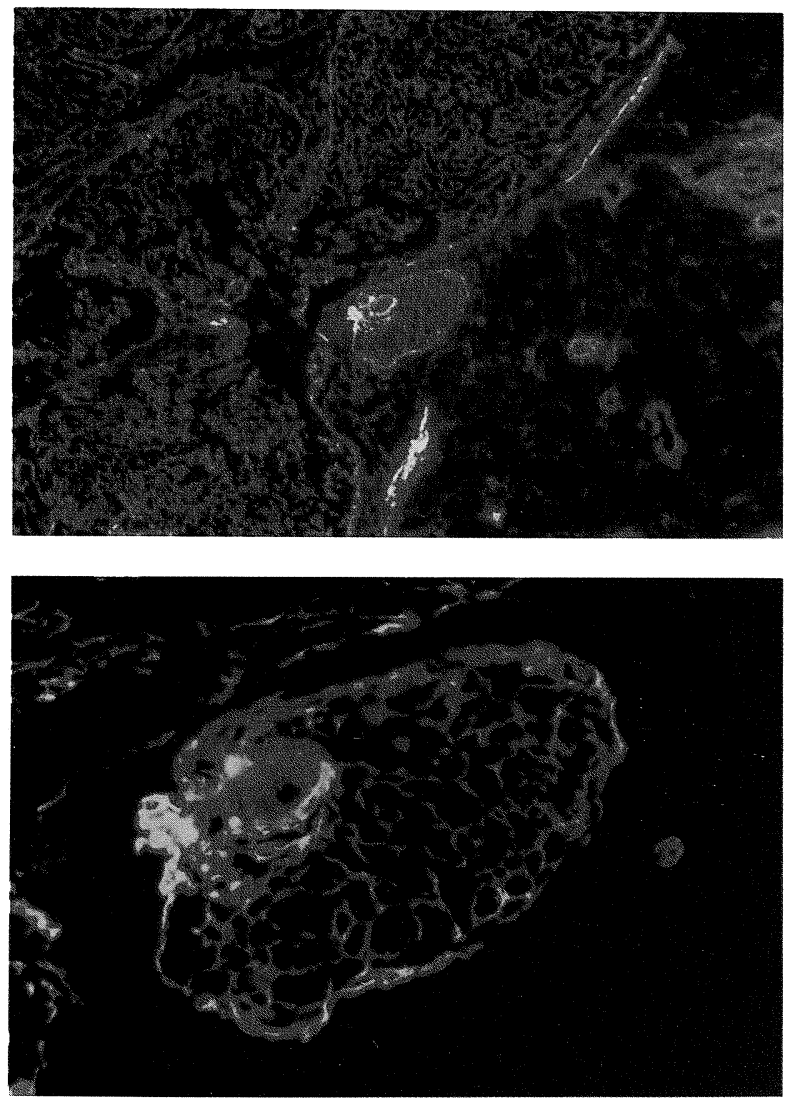

Fig. 3. Immunohistochemical labelling of thymic autograft. Costaining with anti-cytokeratin (red) and anti-neurophysin (green)

thymus was found to be a prerequisite to obtain long-term growth of the xenografts. Tolerance to donor species (minipig) was demonstrated by the survival of skin xenografts from the father of the fetuses whose thymus was used for implantation under the renal capsule [26]. These authors also demonstrated that the xenografted thymic tissue was capable of positively and negatively selecting immature lymphocytes of both donor and host origin in that model.

If we were to apply this procedure in the pig-toprimate model, the growth of minute fetal thymic fragments under the renal capsule would probably be impaired by the high level of antipig xenoantibodies, contrarily to the situation prevailing in the pig-to-mice model. This was indeed the case in a series of fetal pig thymus xenografts that we performed under the renal capsule of baboons (unpublished data).

Excision of both cervical thymus lobes in a weaned piglet is an easy procedure. After discarding the surrounding connective tissue and mincing, the fragments being put together in a syringe, it is possible to retrieve about $10 \mathrm{ml}$ of minced thymus. The amount of thymic tissue that can be grafted un-
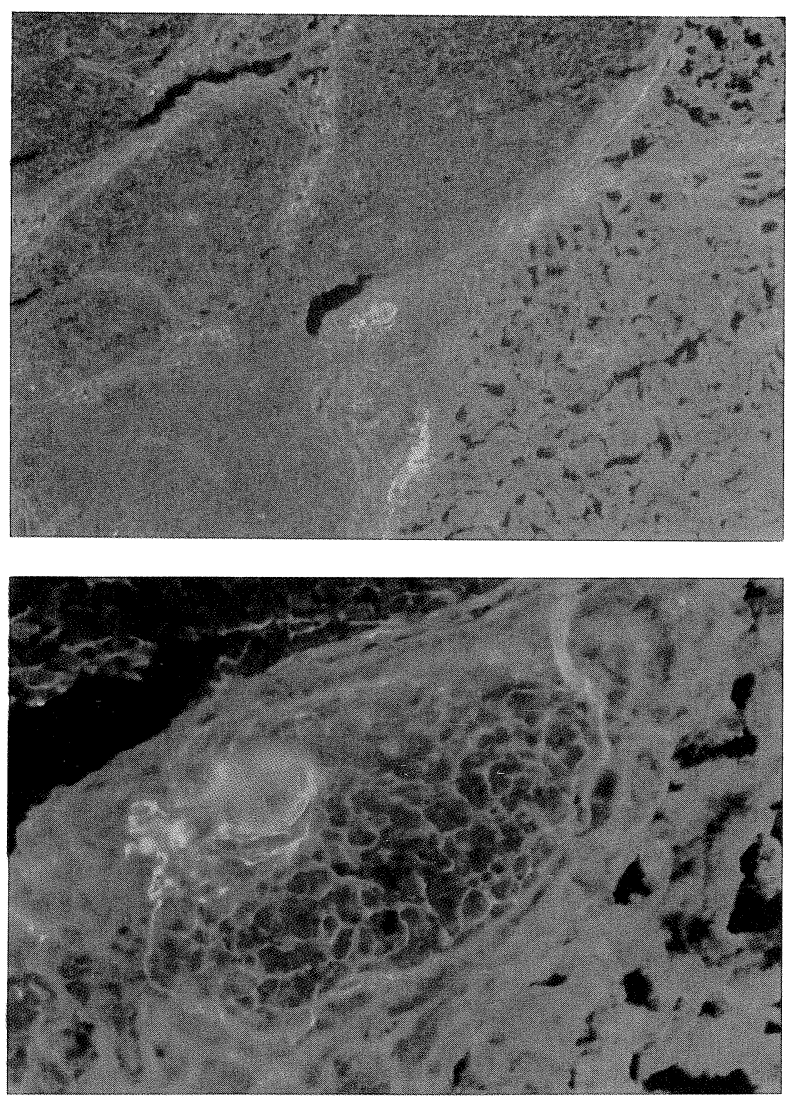

antibodies revealed lobular structures identical to H\&E biopsies and labelling pattern observed in normal human thymus.

der the kidney capsule is therefore far greater than the total amount obtained from a pig fetus.

Therefore, we developed the idea of autografting a larger quantity of pig thymic tissue under the renal capsule in order to allow the autografted tissue to implant itself and to grow in the absence of any immunological interference. A new organ that we named "thymo-kidney" would be so created allowing the transplantation of well developed and functional thymic tissue and kidney in the same time as a sole organ. By so doing it is hoped that induction of xenotolerance will be facilitated.

The main advantage of our procedure results in providing a relative large quantity of well-developed and functional donor thymic tissue at the time of xenografting. Combined with recipient's thymectomy, it is hoped that transient immunosuppression will allow the induction of immunological tolerance. These studies are under way.

This study reports the results of the first step in the development of this idea, i.e., the autografting of pig thymus under the renal capsule. It has been shown that the procedure is straightforward, relatively easy, and efficient. After a few weeks, the au- 


\section{Lambrigts et al.}

tografted thymic tissue develops itself and grow so as to become a well developed and organized tissue bearing all the histological features of a normal pig thymus. Regarding the neurohypophysial peptide family, our group as well as others have shown that thymic epithelial and nurse cells (TEC/TNC) synthesize oxytocin (OT) and its precursor-associated protein, OT-neurophysin [27-29] (OT-NP). Together with cytokeratin immunolabelling of TEC, the neurophysin pattern may be regarded as a criteria of functional epithelial environment. Since the autografted thymic fragments develop after a few weeks into a tissue that shows all the histological and immunohistochemical features of normal pig thymus by the criteria we have used so far, it is logical to hope that this neo-thymus developed under the renal capsule behaves itself indeed functionally as normal pig thymus.

It is clear that transplantation of a functional pig thymus along with and from the same origin as the xenotransplanted organ would offer a method to induce specific immunological tolerance in man towards the organ donor provided sufficient time is given to the thymic component of the graft to exert its functional capabilities after the xenotransplant procedure.

We have demonstrated that pig thymus that has been prepared by this method takes and grow under the kidney capsule of its owner so as to provide a layer up to $4 \mathrm{~mm}$ thick after a few weeks. Obviously, if specific immune xenotolerance may be induced by transplantation of thymus from the specific organ donor, this neo-organ (thymo-kidney) would offer both quantitative and qualitative advantages. Quantitatively, the mass of transplanted thymic tissue would be relatively abundant, representing a layer of several millimeters developed on a relatively high percentage of the kidney surface. Qualitatively, it offers a tissue that is ready to function immediately after transplantation. It contains all the components of normal thymus and would suffer no more damage than those resulting from the surgical maneuvers of the transplant procedure.

No untoward effect was so far discovered that could be related to this procedure. In particular the underlying renal cortex did not show any lesion in any of the biopsies taken at the various intervals after thymus autografting. In a separate experiment, autografting of thymo-kidney was performed with controlateral nephrectomy: the pig is alive and well with normal renal function (manuscript in preparation).

The possibility to induce specific tolerance by this neo-organ remains to be proven. In particular, the tolerogenic capabilities of this neoformed thymus transplanted with the kidney that supports it as a sole organ in a primate model compared with the tolerogenic effect of fetal pig thymus transplanted in mice remains to be confirmed.

\section{Acknowledgments}

This work was supported by the "Fonds Spécial de la Recherche" of the University of Liège and by a grant from the "Fondation Léon Fredericq." The authors thank C. Remy for devoted technical assistance.

\section{References}

1. Niekrasz M, Ye Y, Rolf LL, Zuhdi N, Cooper DKC. The pig as organ donor for man. Transplant Proceed 1992:24:625.

2. CoOper DKC, Ye Y, Rolf JR, Zuhdi N. The pig as potential donor for man. In: Cooper DKC, Kemp E, Reemtsma $\mathrm{K}$, White DJG, eds. Xenotransplantation. Springer-Verlag 1991, chapter 30, pp 481-500.

3. CALNE RY. Organ transplantation between widely disparate species. Transplant Proc 1970:2:550.

4. Murray AG, Khodadoust MM, Pober JS, Bothwell AL. Porcine aortic endothelial cells activate human T cells: direct presentation of $\mathrm{MHC}$ antigens and costimulation by ligands for human CD 2 and CD 28. Immunity 1994:1:57.

5. Kumagai-Braesch M, Satake M, Korsgren O, Andersson A, MÖLLER E. Characterization of cellular human anti-porcine xenoreactivity. Clin Transplantation 1993:7:273-280.

6. Yamada K, Sachs DH, DerSimonian H. Direct and indirect recognition of pig class II antigens by human T cells. Transplan Proc 1995:27:258.

7. Auchincloss H. Why is cell-mediated xenograft rejection so strong? Xeno 1995:3:19.

8. Alexandre GPJ, De Bruyère M, Squifflet JP, Moriau M, Latinne D, Pirson Y. Human ABO-incompatible living donor renal homografts. Neth J Med 1985:28-231.

9. Alexandre GPJ, Gianello P, Latinne D, Carlier M, Dewaele A, Van Obbergh L, Moriau M, Marbaix E, Lambotte JL, Lambotte L, Squifflet JP. Plasmapheresis and splenectomy in experimental renal xenotransplantation. In "Xenograft 25," Mark A. Hardy, ed. New York: Elsevier, 1989:259.

10. Alexandre GPJ, Gianello P, Latinne D, Cosijns P, Carlier M, Squifflet JP. Pig to baboon model in renal xenotransplantation. Minerva Chir 1991:46:101.

11. Alexandre GPJ, Squifflet JP, De Bruyère M, Latinne D, Reding R, Gianello P, Carlier M, Pirson Y. Present experiences in a series of $26 \mathrm{ABO}$-incompatible living donor renal allografts. Transplant Proceed XIX:1987:4538.

12. Platt JL, BACH FH. The barrier to xenotransplantation. Transplantation 1991:52:937.

13. Alexandre GPJ, Latinne D, Carlier M, Moriau M, Pirson Y, GiANELlo P, SQUifFlet JP. ABO-Incompatibility and organ transplantation. Transplantation Reviews 1991:5:4:230.

14. ILDSTAD ST, SACHS DH. Reconstitution with syngeneic plus allogeneic or xenogeneic bone marrow leads to specific acceptance of allografts or xenografts. Nature 1984:307-168.

15. Sykes M, Sachs DH. Mixed allogeneic chimerism as an approach to transplantation tolerance. Immunology Today 1988:9:23.

16. Lee LA, Gritsch A, Sergio JJ, Arn S, Glaser RM, SABLINSKI T, SACHS DH, SyKes M. Specific tolerance across a discordant xenogeneic transplantation barrier. Proc Natl Acad Sci USA 1994:91:10864.

17. Sykes M, Lee LA, Sachs DH. Xenograft tolerance. Immunol Rev 1994:141:245. 


\section{New "organ" for xenotransplantation}

18. Legros J-J. Les neurophysines: Recherches méthodologiques, expérimentales et cliniques. Masson eds, Paris, 1976.

19. Burgeon E, Chapleur M, Schoenen J, Remichius D, Legros JJ, GeEnen V, Robert F. Monoclonal antibodies to oxytocin: production and characterization. J. Neuroimmunology 1991:31:235.

20. Robert F, Geenen V, Schoenen J, Burgeon E, De Groot D, Defresne MP, Legros JJ, Franchimont P. Colocalization of immunoreactive oxytocin, vasopressin and interleukin1 in human thymic epithelial neuroendocrine cells. Brain Behav Immunol 1991:5:102.

21. Rydberg L, Hallberg E, Buörck S, Magnusson S, Strokan V, Samuelsson BE, Breimer ME. Studies on the removal of anti-pig xenoantibodies in the human by plasmapheresis/immunoadsorption. Xenotransplantation 1995:2:253.

22. Sablinsky T, Lorf T, Monroy R, Bailin M, Gianello P, Cosimi B, SACHS DH. Absorption of primate anti-swine antibodies by extracorporeal perfusion through Gal $\alpha(1,3)$ Gal columns. Transplant Proceed (in press).

23. Tuso PJ, Cramer DV, Yasunaga C, Sosenza CA, Wu GD, MaKowka L. Removal of natural human xenoantibodies to pig vascular endothelium by perfusion of blood through pig kidneys and livers. Transplantation 1993:55:1375.

24. Neethling FA, Koren E, Ye Y, Richards SV, Kujundzic M, OrIOL R, COOPER DKC. Protection of pig kidney (PK15) cells from the cytotoxic effect of anti-pig antibodies by $\alpha$-galactosyl oligosaccharides. Transplantation 1994:57:959.

25. Alexandre GPJ, Latinne D, Gianello P, Souifflet JP. Preformed cytotoxic antibodies and ABO-Incompatible grafts. Clin Transplantation 1991:5:583.

26. Khan A, Sergio JJ, Zhao Y, Pearson DA, Sachs DH, SYKES M. Discordant xenogeneic neonatal thymic transplantation can induce donor-specific tolerance. Transplantation 1996, in press.

27. Geenen V, Legros J-J, Franchimont P, Baudrihaye M, Defresne M-P, Boniver J. The neuroendocrine thymus: Coexistence of oxytocin and neurophysin in the human thymus. Science 1986:232:508.

28. Wiemann M, Ehret G. Subcellular localization of immunoreactive oxytocin within thymic epithelial cells of male mouse. Cell Tissue Res. 1993:273:79.

29. Martens H, Goxe B, Geenen V. The thymic repertoire of neuroendocrine self-antigens: physiological implications in T-cell life and death. Immunol. Today 1996:17:312. 